\title{
Reduced serum tetanus antibody titre in HIV infected subjects with malaria co-infection in a malaria endemic area of Nigeria
}

\author{
C.C. ONYENEKWE ${ }^{1 *}$, N.R. UKIBE ${ }^{2}$, S.C. MELUDU ${ }^{2}$, A.O. IGWEGBE ${ }^{3}$, P. ELE ${ }^{4}$, \\ M. IFEANYI ${ }^{5}$, A. ONOCHIE $^{6}$, M. EZEANI ${ }^{5}$ and N. OFIAELI $^{7}$ \\ ${ }^{1}$ Department of Medical Laboratory Sciences, College of Health Sciences, Nnamdi Azikiwe University, Nnewi \\ Campus, PMB 5001 Nnewi, Anambra State, Nigeria. \\ ${ }^{2}$ Department of Human Biochemistry, College of Health Sciences, Nnamdi Azikiwe University, Nnewi Campus, \\ PMB 5001 Nnewi, Anambra State, Nigeria. \\ ${ }^{3}$ Department of Obstetric and Gynaecology, College of Health Sciences, Nnamdi Azikiwe University, Nnewi \\ Campus, PMB 5001 Nnewi, Anambra State, Nigeria. \\ ${ }^{4}$ Department of Medicine, College of Health Sciences, Nnamdi Azikiwe University, Nnewi Campus, PMB 5001 \\ Nnewi, Anambra State, Nigeria. \\ ${ }^{5}$ Department of Immunology, College of Health Sciences, Nnamdi Azikiwe University, Nnewi Campus, PMB \\ 5001 Nnewi, Anambra State, Nigeria. \\ ${ }^{7}$ VCT Unit, Nnamdi Azikiwe University Teaching Hospital, Nnewi, Anambra State, Nigeria. \\ ${ }^{6}$ Department of Biochemistry, Anambra State University of Science and Technology, Uli, Anambra State, \\ Nigeria. \\ *Corresponding author, E-mail: charleschinedum2002@yahoo.com
}

\begin{abstract}
Tetanus infection is widespread and difficult to completely eradicate. Thus the present study was designed to assess the tetanus antibody titre in HIV infected subjects in relation to the presence or absence of malaria parasitaemia. 107 subjects consisting of asymptomatic group (asymptomatic HIV, $\mathrm{n}=17$ and asymptomatic HIV-Malaria co-infection, $\mathrm{n}=17$ ), symptomatic group (symptomatic HIV, $\mathrm{n}=18$ and symptomatic HIV-Malaria co-infection, $\mathrm{n}=17$ ), and control group (control without malaria, $\mathrm{n}=19$ and control with malaria, $n=19$ ) participated in the study. Blood sample collected from the participants were used for the determination of packed cell volume, $\mathrm{CD}^{+} \mathrm{T}$ cell count, malaria parasite, HIV seropositivity and tetanus antibody titre using standard laboratory methods. The tetanus antibody titre was significantly reduced in symptomatic HIV infected subjects with malaria co-infection compared with symptomatic HIV infected subjects without malaria $(\mathrm{P}<0.05)$. Similarly, both groups of asymptomatic and symptomatic HIV infected subjects had reduced serum tetanus antibody titre compared with the seronegative control subjects and group with malaria parasitaemia $(\mathrm{P}<0.05)$. The $\mathrm{CD} 4^{+} \mathrm{T}$ cell count and packed cell volume were similar between the asymptomatic HIV infected subjects with malaria and those with only HIV. This was also the case for the symptomatic groups. The finding of the present study suggests that either HIV or malaria infections do interfere with the tetanus antibody titre. The increasing spread of HIV in malaria endemic areas may pose further threat to the current programmes on immunization targeted at eliminating tetanus infection.
\end{abstract}

(C) 2008 International Formulae Group. All rights reserved.

Keywords: HIV; Malaria; Vaccine; Human.

\section{INTRODUCTION}

In Nigeria, pregnant women attending antenatal clinic and children visiting immunization centres are placed on scheduled tetanus toxoid immunization. The purpose is to generate high titre of tetanus antibody, which confers protective immunity. However, this purpose may not be achieved in immunocompromised individuals (Gibb et al., 1995, 1996). Other factors such as nutritional 
stability and chronic infections may also play a role in achieving acquired protective immunity after immunization. Presently, literatures exist that show increasing prevalence of HIV and Malaria co-infection particularly in endemic areas of Sub-Saharan Africa (Grimwade et al., 2003; Grimwade et al., 2004; Abu-Radad et al., 2007; Onyenekwe et al., 2007). The incidence of both infections in any individual has been shown to be severe (Cohen et al., 2005; Onyenekwe et al., 2008a). Previously, we had reported that tetanus antibody titre were not impaired in pregnant women with malaria parasites but with no malaria symptom compared with the titre in aparasiteamic pregnant women (Onyenekwe et al., 2003). Recently we have reported reduced anti-BCG titre in HIV and malaria coinfected or HIV infected subjects (Onyenekwe et al., 2008b). However, could this observation of impaired antibody titre be a generalized or selective phenomenon in HIV infection? This question if explored may yield vital information on generation of acquired protective immunity in HIV infected subjects. Therefore, the present study was designed to assess the tetanus antibody titre in subjects with HIV and malaria co-infection.

\section{MATERIALS AND METHODS Subjects}

A total of 107 subjects aged between 17 and 60 years participated in the study. The participants were randomly recruited. They were double screened for HIV infection and double screened for malaria parasites. Using the WHO criteria for staging HIV, participants with HIV infection were classified into groups as:

a) Symptomatic HIV $(n=35)$ consist of subjects with HIV and Malaria co-infection $(n=17)$ and subjects with only HIV infection $(\mathrm{n}=18)$.

b) Asymptomatic HIV $(n=34)$ consist of subjects with HIV and Malaria co-infection $(n=17)$ and subjects with only HIV infection $(\mathrm{n}=17)$.

c) The remaining participants were HIV seronegative and were referred to as control subjects $(n=38)$. They consist of malaria infected $(\mathrm{n}=19)$ and uninfected individuals $(n=19)$.

Blood samples were collected from all the participants for HIV and malaria screening and for the analysis of packed cell volume (PCV), white blood cell count (WBC), CD4 ${ }^{+}$ $\mathrm{T}$ cell count and determination of anti-tetanus toxoid titre. The participants gave informed consent while the Board of ethical committee approved the study design.

\section{Detection of antibodies to HIV-1 and HIV-2 in human plasma \\ The immunoassay (Abbott Japan Co} Ltd. Tokyo, Japan) and immunochromatographic (CHEMBIO diagnostic system, Inc. New York USA) methods were used for the HIV double screening. For the Abbott determination of HIV-1 and HIV-2, the procedure described by the manufacturer was used for the analysis. In brief, $50 \mu$ l of plasma sample collected from participants in the study were applied to the appropriately labelled sample pad. After 15 minutes the results were read. This method is an in vitro visually read immunoassay. The method has inherent quality control that validates the results. The procedure for the immunochromatographic method was as described by the manufacturer. Briefly, $5 \mu 1$ of participants' plasma were dispensed into appropriately labelled sample pads and 3 drops of the buffer supplied by the manufacturer was added into each sample pad. The results of the test were read at 10 minutes after the addition of the running buffer. The method has inherent quality control that validates the results. The HIV seropositive results obtained using these two methods were used to classify participants having HIV infection. This method of double HIV screening has been previously described by Onyenekwe et al. (2007).

\section{Diagnosis of Plasmodium falciparum malaria}

The $P$. falciparum malaria was diagnosed using Rapid Test device (Para check, Orchid Biomedical system, Vena Goa, India) and microscopic detection of parasites in Giemsa stained thick blood film. The parasites density was determined as previously described by Onyenekwe et al. (2002) and the parasite density was expressed per litre of blood. The principle of the rapid diagnostic test for malaria antigen is based on rapid chromatographic immunoassay. The method utilizes gold conjugate to selectively 
detect Plasmodium antigen. The procedure used was that described by the manufacturer. Briefly, $10 \mu \mathrm{l}$ of whole blood collected from the participants were dispensed into appropriately labelled specimen cassettes. After which 3 drops of the buffer supplied by the manufacturer was added to each of the specimen cassettes and the results determined after 15 minutes of addition of the buffer. The test result has inherent quality control that validates the results. The rapid test device method for malaria has been previously described by Onyenekwe et al. (2007).

Similarly the method for $\mathrm{CD}^{+} \mathrm{T}$ cell count using the Cyflow machine and the method for determination of the packed cell volume (PCV) using microhaematocrit centrifuge was as previously described by Onyenekwe et al. (2008a).

Determination of serum tetanus antibody titre using haemagglutination technique

In brief, pooled $\mathrm{O}^{+}$blood sample was used to prepare $5 \%$ red cell suspension. Pooled sample was washed thrice in normal saline after several washings in normal saline. Tetanus toxoid vaccine was used to coat or sensitize the washed red cells by incubating the tetanus toxoid-red cell mixture at $37{ }^{\circ} \mathrm{C}$ for 90 minutes. After the incubation period, the tetanus toxoid sensitized red cells were washed to remove any unbound tetanus toxoid antigen. Subsequently $5 \%$ suspension of the tetanus toxoid-sensitized red cells was prepared for the purposes of the haemagglutination test. For the haemagglutination test, the serum samples were diluted accordingly and equal volumes of the tetanus toxoid-sensitized red cells were added to the various dilutions of the samples in order to determine the tetanus antibody titre for each serum. The serum-tetanus toxoid-sensitized red cells were incubated at $37{ }^{\circ} \mathrm{C}$ for 120 minutes. The maximum serum dilution providing a positive haemagglutination result on the basis of the presence of macroscopic and microscopic agglutination was recorded.

\section{Statistical analysis}

Variables were expressed in mean $( \pm \mathrm{SD})$ while the student t-test was used to determine significant mean difference. The Spearman correlation coefficient was used to assess the level of association between variables. Significant level was considered at $\mathrm{P}<0.05$.

\section{RESULTS}

The mean $( \pm \mathrm{SD})$ malaria parasite density per litre of blood were 2.72 \pm 2.45 $\left(\mathrm{x} 10^{6}\right)$ in asymptomatic HIV infected subjects with malaria co-infection; $3.36 \pm 2.45\left(\times 10^{6}\right)$ in symptomatic HIV infected subjects with malaria co-infection and $3.99 \pm 2.37\left(\times 10^{6}\right)$ in HIV seronegative control subjects with malaria infection. The malaria parasite density in these groups was not significantly different (Tables 1 and 2).

There was no significant $(\mathrm{P}>0.05)$ mean difference in tetanus antibody titre between the asymptomatic HIV infected subjects with malaria co-infection and asymptomatic HIV subjects. However, the tetanus antibody titre was significantly $(\mathrm{P}<0.01)$ reduced in the symptomatic HIV infected subjects with malaria co-infection compared with the symptomatic HIV infected subjects. Similarly, the mean tetanus antibody titre was significantly $(\mathrm{P}<0.05)$ reduced in HIV seronegative control subjects with malaria infection compared with HIV seronegative control subjects without malaria infection (Table 1). The mean tetanus antibody titre was significantly $(\mathrm{P}<0.05)$ reduced in both the symptomatic and asymptomatic groups compared with values in the corresponding control groups. However, the mean tetanus antibody titre in symptomatic HIV group was not significantly ( $P>0.05)$ different from value observed in asymptomatic HIV group. Similarly, there was no significant $(\mathrm{P}>0.05)$ mean difference in tetanus antibody titre between symptomatic HIV group with malaria co-infection and asymptomatic HIV group with malaria coinfection (Table 3 ).

The mean $( \pm \mathrm{SD}) \mathrm{CD}^{+} \mathrm{T}$ cell count was not significantly different between the symptomatic HIV infected subjects and symptomatic HIV and malaria co-infected subjects. There was also no significant mean difference in the packed cell volume between these two groups. There was also no significant difference in the $\mathrm{CD} 4^{+} \mathrm{T}$ cell count between the HIV seronegative control subjects with malaria and those without malaria; and between the asymptomatic HIV and 
Table 1: Mean $( \pm \mathrm{SD})$ malaria parasite density $\left(\mathrm{x} 10^{6} / \mathrm{l}\right), \mathrm{CD}^{+} \mathrm{T}$ cell count $\left(/ \mathrm{mm}^{3}\right), \mathrm{PCV}(\%)$ and serum tetanus antibody titre in asymptomatic, symptomatic and control groups.

\begin{tabular}{|c|c|c|c|c|}
\hline Parameters & Titre & MP density & PCV & $\begin{array}{c}\mathrm{CD}^{+} \mathrm{T} \text { cell } \\
\text { count }\end{array}$ \\
\hline \multicolumn{5}{|l|}{ Asymptomatic group } \\
\hline Asymptomatic HIV-malaria $(\mathrm{n}=17)$ & $147 \pm 119$ & $2.72 \pm 2.45$ & $34.0 \pm 7.5$ & $320 \pm 149$ \\
\hline Asymptomatic HIV $(\mathrm{n}=17)$ & $216 \pm 205$ & - & $33.6 \pm 5.3$ & $427 \pm 237$ \\
\hline$P$-value & $>0.05(n s)$ & $n c$ & $>0.05(n s)$ & $>0.05(n s)$ \\
\hline \multicolumn{5}{|l|}{ Symptomatic group } \\
\hline Symptomatic HIV-malaria $(n=17)$ & $105 \pm 131$ & $3.36 \pm 2.45$ & $31.2 \pm 5.2$ & $251 \pm 160$ \\
\hline Symptomatic HIV $(\mathrm{n}=18)$ & $345 \pm 199$ & - & $32.4 \pm 4.6$ & $255 \pm 149$ \\
\hline P-value & $<0.01$ & $n c$ & $>0.05(n s)$ & $>0.05(n s)$ \\
\hline \multicolumn{5}{|l|}{ Control group } \\
\hline Control with Malaria $(n=19)$ & $317 \pm 246$ & $3.99 \pm 2.37$ & $40.3 \pm 4.8$ & - \\
\hline Control without Malaria $(n=19)$ & $593 \pm 379$ & - & $39.1 \pm 5.6$ & - \\
\hline P-value & $<0.05$ & $n c$ & $>0.05(n s)$ & - \\
\hline
\end{tabular}

Key: ns = not significant; $\mathrm{nc}=$ not compared.

Table 2: Comparison of mean $( \pm \mathrm{SD})$ malaria parasite density $\left(\times 10^{6} / 1\right), \mathrm{CD} 4^{+} \mathrm{T}$ cell count $\left(/ \mathrm{mm}^{3}\right)$, PCV (\%) and serum tetanus antibody titre between asymptomatic, symptomatic and control groups.

\begin{tabular}{lcccc}
\hline Parameters & Titre & MP density & PCV & $\begin{array}{c}\text { CD4 } \\
\text { count }\end{array}$ \\
\hline Asymptomatic HIV-malaria & $147 \pm 119$ & $2.72 \pm 2.45$ & $34.0 \pm 7.5$ & $320 \pm 149$ \\
Control with Malaria & $317 \pm 246$ & $3.99 \pm 2.37$ & $40.3 \pm 4.8$ & - \\
$\boldsymbol{P}$-value & $\boldsymbol{p}<\mathbf{0 . 0 5}$ & $\boldsymbol{P}>\mathbf{0 . 0 5}(\boldsymbol{n s})$ & $\boldsymbol{P}<\mathbf{0 . 0 5}$ & $\boldsymbol{n c}$ \\
\hline Symptomatic HIV-malaria & $105 \pm 131$ & $3.36 \pm 2.45$ & $31.2 \pm 5.2$ & $251 \pm 160$ \\
Control with Malaria & $317 \pm 246$ & $3.99 \pm 2.37$ & $40.3 \pm 4.8$ & - \\
$\boldsymbol{P}$-value & $\boldsymbol{p}<\mathbf{0 . 0 5}$ & $\boldsymbol{P}>\mathbf{0 . 0 5}(\boldsymbol{n s})$ & $\boldsymbol{P}<\mathbf{0 . 0 5}$ & $\boldsymbol{n c}$ \\
\hline Asymptomatic HIV & $216 \pm 205$ & - & $33.6 \pm 5.3$ & $427 \pm 237$ \\
Control without Malaria & $593 \pm 379$ & - & $39.1 \pm 5.6$ & - \\
$\boldsymbol{P}$-value & $\boldsymbol{p}<\mathbf{0 . 0 5}$ & $\boldsymbol{n c}$ & $\boldsymbol{P}<\mathbf{0 . 0 5}$ & $\boldsymbol{n c}$ \\
\hline Symptomatic HIV & $345 \pm 199$ & - & $32.4 \pm 4.6$ & $255 \pm 149$ \\
Control without Malaria & $593 \pm 379$ & - & $39.1 \pm 5.6$ & - \\
$\boldsymbol{P}$-value & $\boldsymbol{p}<\mathbf{0 . 0 5}$ & $\boldsymbol{n c}$ & $\boldsymbol{P}<\mathbf{0 . 0 5}$ & $\boldsymbol{n c}$ \\
\hline \multicolumn{2}{c}{ Key: ns = not significant; nc $=$ not compared. } & &
\end{tabular}

Table 3: Comparison of mean $( \pm \mathrm{SD})$ malaria parasite density $\left(\times 10^{6} / 1\right), \mathrm{CD}^{+} \mathrm{T}$ cell count $\left(/ \mathrm{mm}^{3}\right)$, PCV $(\%)$ and serum tetanus antibody titre between asymptomatic and Symptomatic groups.

\begin{tabular}{|c|c|c|c|c|}
\hline Parameters & Titre & MP density & PCV & $\begin{array}{c}\mathrm{CD}^{+} \mathrm{T} \text { cell } \\
\text { count }\end{array}$ \\
\hline Asymptomatic HIV & $216 \pm 205$ & - & $33.6 \pm 5.3$ & $427 \pm 237$ \\
\hline Symptomatic HIV & $345 \pm 199$ & - & $32.4 \pm 4.6$ & $255 \pm 149$ \\
\hline$P$-value & $p>0.05(n s)$ & $n c$ & $p>0.05(n s)$ & $p<0.05$ \\
\hline Asymptomatic HIV-malaria & $147 \pm 119$ & $2.72 \pm 2.45$ & $34.0 \pm 7.5$ & $320 \pm 149$ \\
\hline Symptomatic HIV-malaria & $105 \pm 131$ & $3.36 \pm 2.45$ & $31.2 \pm 5.2$ & $251 \pm 160$ \\
\hline p-value & $p>0.05(n s)$ & $p>0.05(n s)$ & $P>0.05(n s)$ & $p>0.05(n s)$ \\
\hline
\end{tabular}


asymptomatic HIV with malaria co-infection. There was also no significant mean difference in packed cell volume between these respective groups as defined above (Table 1, 2 and 3). However, the mean packed cell volume was significantly $(\mathrm{P}<0.05)$ reduced in the symptomatic and asymptomatic groups compared with their corresponding control groups (Table 2).

A significant positive association was observed between the tetanus antibody titre and packed cell volume $(\mathrm{r}=0.473 ; \mathrm{P}<0.05)$ in symptomatic HIV infected subjects while a positive association was observed between the $\mathrm{CD}^{+} \mathrm{T}$ cell count and malaria parasite density $(\mathrm{r}=0.640 ; \mathrm{P}<0.05)$ in symptomatic HIV infected subjects with malaria coinfection.

\section{DISCUSSION}

The mean malaria parasite density observed in the present study did not suggest increased malaria parasitaemia in subjects infected with HIV. This may be a consequence of age influenced acquired protective immunity often seen in adults residing in malaria endemic area. The participants in the present study fall into similar age range. However, the malaria specific antibodies were not analyzed in the present study. It may therefore be necessary to assess the malaria specific antibodies in such individuals with the co-morbidity.

The tetanus antibody titre was generally reduced in both the subjects presenting HIV and malaria co-morbidity and those presenting only HIV infection. However, from the result of the tetanus antibody titre in the control subjects, malaria infection seems also to interfere with the acquired protective tetanus antibody titre. However, the interaction of both HIV and malaria infections on the tetanus antibody titre was prominent among the symptomatic group although the tetanus antibody titre in the symptomatic HIV infected subjects with malaria was comparable to that seen amongst the asymptomatic HIV infected subjects with malaria. Thus increasing prevalence of HIV infection in malaria endemic area of SubSaharan Africa may pose danger to the massive tetanus toxoid immunization programme targeted at reducing the incidences of tetanus infection. This is because protection against tetanus infection is antibody mediated.

Study elsewhere has shown impaired tetanus antibody titre in HIV-1 infected subjects (Tatiana et al., 2004). Furthermore, tetanus antibody titre was considerably reduced in HIV infected subjects with $\mathrm{CD}^{+} \mathrm{T}$ cell count of less than $300 \times 10^{6} / 1$ (Kroon et al., 1995). In the present study reduced tetanus antibody titre was seen in asymptomatic HIV subjects with or without malaria co-infection even though the mean $\mathrm{CD} 4^{+} \mathrm{T}$ cell count was slightly above $300 \times 10^{6} / 1$. This was also the case for symptomatic HIV subjects with or without malaria co-infection although their mean $\mathrm{CD}^{+} \mathrm{T}$ cell count was below $300 \mathrm{x}$ $10^{6} / 1$. This could mean that other factors may have roles in adjusting the tetanus antibody titre but not just a CD4 ${ }^{+} \mathrm{T}$ cell count cut-off.

It has been reported that acute malaria infection does affect the response to tetanus toxoid immunization (Jennifer et al., 2004). However, whether or not there is improvement in anti-tetanus titre after malaria treatment is still in a contentious issue (Fryauff et al., 1998; Jennifer et al., 2004; Rosen et al., 2005).

In our previous report we did not observe any impaired anti-tetanus titre in pregnant women with malaria parasite with no malaria symptom compared with uninfected pregnant women (Onyenekwe et al., 2003). Although it is clearly evident that the level of parasitaemia encountered amongst the control subjects in the present study was much higher than that previously reported in the pregnant women with asymptomatic malaria parasitaemia. Thus, the intensity of parasitaemia may likely be a strong factor that affects anti-tetanus titre in malaria endemic areas. This is because all our studied groups had similar malaria parasite densities.

HIV infected pregnant women with malaria infection have shown inability to transfer tetanus specific IgG in-utero to the foetus due to inadequate generation of specific tetanus antibody during antenatal immunization (Cumberland et al., 2007; Moss et al., 2007). The inadequate tetanus antibody titre may partly be due to unresponsiveness of $\mathrm{B}$ cells which is a common phenomenon in HIV infection (Hart et al., 2007). HIV infection has been shown to affect the antigen recall ability of B cells (Gibbs et al., 1995; 
Rosenblatt et al., 2005). However, some level of recovery has been reported during antiretroviral therapy (ART) (Kim et al., 2001; Rosenblatt et al., 2005).

Although the PCV was consistently reduced in asymptomatic HIV subjects with or without malaria co-infection and in symptomatic HIV subjects with or without malaria co-infection, their values were similar in both groups. This finding was consistent with our earlier report that packed cell volume was similar in subjects with HIV infection and HIV-malaria co-infection (Onyenekwe et al., 2008a). The association observed between tetanus antibody titre and packed cell volume in the symptomatic HIV subjects calls for further study in order to determine the implication of such association.

The finding of the present study suggests that either HIV or malaria infections do interfere with the tetanus antibody titre. The increasing spread of HIV in malaria endemic areas may pose further threat to the current programmes on immunization targeted at eliminating tetanus infection.

\section{REFERENCES}

Abu-Radded LJ, Patnaik P, Kublin JG. 2007. Dual infection with HIV and malaria fuels the spread of both diseases in subSaharan Africa. Science, 315: 598.

Cohen C, Karstaedt A, Frean J, Thomas J, Govender N, Prentice E, Dini L, Galpin J, Crewe-Brown H. 2005. Increased prevalence of severe malaria in HIVinfected adults in South Africa. Clin Infect. Dis., 41: 1631-1637.

Cumberland P, Shulman CE, Maple PA, Bulmer JN, Dorman EK, Kawuondo K, Marsh K, Cutts FT. 2007. Maternal HIV infection and Placental malaria reduce transplacental antibody transfer and tetanus antibody levels in newborns in Kenya. J. Infect. Dis., 196: 550-557.

Fryauff DJ, Cryz SJ, Widjaja H, Mouzin E, Church LW, Sutamihardja MA, Richards AL, Subianto B, Hoffman SL 1998. Humoral immune response to tetanusdiphtheria vaccine given during extended use of chloroquine or primaquine malaria chemoprophylaxis. J. Infect. Dis., 177: 1762-1765.

Gibb D, Giacomelli A, Masters J, Spoulou V, Ruga E, Griffiths H, Kroll S, Giaquinto
C, Goldblatt D. 1996. Persistence of antibody responses to Haemophilus influenzae type b polysaccharide conjugate vaccine in children with vertically acquired human immunodeficiency virus infection. Pediatr. Infect. Dis. J., 15: 1097-1101.

Gibb D, Spoulou Y, Giacomelli A, Griffiths H, Masters J, Misbah S, Nokes L, Pagliaro A, Giaquinto C, Kroll S. 1995. Antibody responses to Haemophilus influenzae type $\mathrm{b}$ and Streptococcus pneumoniae vaccines in children with human immunodeficiency virus infection. Pediatr. Infect. Dis. J., 14: 129-135.

Grimwade K, French N, Mbatha DD, Zungu DD, Dedicoat M, Gilks CF. 2003. Childhood malaria in a region of unstable transmission and high human immunodeficiency virus prevalence. Pediatr. Infect. Dis. J., 22: 1057-1063.

Grimwade K, French N, Mbatha DD, Zungu DD, Dedicoat M, Gilks CF. 2004. HIV infection as a co-factor for severe falciparum malaria in adults living in a region of unstable malaria transmission in South Africa. AIDS, 18: 547-554.

Hart M, Steel A, Clark SA, Moyle G, Nelson M, Henderson DC, Wilson R, Gotch F, Gazzard B, Kelleher P. 2007. Loss of discrete memory B cell subsets is associated with impaired immunization responses in HIV-1 infection and may be a risk factor for invasive pneumococcal disease. J. Immunol., 178: 8212-8220.

Jennifer BR, Joel GB. 2004. Malaria intermittent preventive treatment in infants, chemoprophylaxis, and childhood vaccinations. Rapid Review. The Lancet: 1386-1388.

Kim J H, Mascola J R, Ratto-Kim S, VanCott T C, Loomis-Price L, Cox J H, Michael N L, Jagodzinski L hawkes C, Mayers D, Gilliam B L, Birx D C, Robb M L. 2001. Selective increases in HIV-specific neutralizing antibody and partial reconstitution of cellular immune responses during prolonged successful drug therapy of HIV infection. AIDS Res. Hum. Retroviruses, 17: 1021-1034.

Kroon FP, van Dissel JT, Labadie J, van Loon AM, van Furth R, 1995. Antibody response to diphtheria, tetanus, and 
poliomyelitis vaccines in relation to the number of $\mathrm{CD}^{+} \mathrm{T}$ lymphocytes in adults infected with human immunodeficiency virus. Clin. Infect. Dis., 21: 1197-1203.

Moss WJ, Halsey NA. 2007. The effects of malaria and HIV-1 infection on the effort to eliminate neonatal tetanus. J. Infect. Dis., 196: 502-504.

Onyenekwe C.C, Ukibe N, Meludu SC, Ifeanyi M, Ezeani M, Onochie A, Ofiaeli N, Aboh N, Ilika A. 2008a. Possible biochemical impact of malaria infection in subjects with HIV co-infection in Anambra state, Nigeria. J. Vector Borne Dis., 45: 151-156.

Onyenekwe CC, Arinola OG, Salimonu LS. 2002. Detection of Plasmodium falciparum- $\mathrm{IgG}$ and incidence of asymptomatic malaria in pregnant women in Nigeria. Indian J. Malariol., 39: 39-42.

Onyenekwe CC, Meludu SC, Arinola OG, Salimonu LS. 2003. Tetanus toxoid antibody level in asymptomatic plasmodium falciparum malaria parasitaemic pregnant women. Afr. J. Biomed. Research., 6: 73-77.

Onyenekwe CC, Ukibe N, Meludu SC, Ilika A, Aboh N, Ofiaeli N, Ezaeni M, Onochie A. 2007. Prevalence of malaria as co-infection in HIV infected individuals in a malaria endemic area of
Southeastern Nigeria. J. Vector Borne Dis., 44: 250-254.

OnyenekweCC, Ukibe N, Meludu S C, Ezeani M, Ofiaeli N, Onochie A, Ilika A, Ifeanyi M, Aboh N, Ele P. 2008b. Serum Levels of anti-BCG, Albumin and Packed Cell Volume and White Blood Cell Count in Subjects with HIV and Malaria Comorbidity. Tropical Medicine and Health, 36: 17-22.

Rosen JB, Breman JG, Manclark CR, Meade BD, Collins WE, Lobel HO, Saliou P, Roberts JM, Campore P, Miller MA. 2005. Malaria chemoprophylaxis and the serologic response to measles and diphtheria-tetanus-whole-cell pertussis vaccines. Malar. J., 4: 53.

Rosenblatt HM, Song LY, Nachman SA, Stanley KE, Krogstad PA, Johnson GM, Wiznia AA, Pediatric Aids clinical Trials Group 377 Study Team. 2005. Tetanus immunity after diphtheria, tetanus toxoids, and acellular pertussis vaccination in children with clinically stable HIV infection. J. Allergy Clin. Immunol., 116: 698-703.

Tatiana CS, Bonetti, Regina CM, Succi, Lily Y, Weckx L, Tavares-Lopes, Isabel de M. 2004. Tetanus and diphtheria antibodies and response to a booster dose in Brazilian HIV-1 infected women. Vaccine, 22: 3707-3712. 